\title{
Estratégias para superar as dificuldades da leitura infantil
}

\author{
Strategies to overcome the difficulties of child reading
}

Estrategias de lectura para superar las dificultad de lectores

Ivana Esteves Passos de Oliveira ${ }^{1}$, Keliene Pedrosa Mirandola Silva ${ }^{2 *}$.

\section{RESUMO}

Objetivo: Revisar a literatura científica sobre o ensino das estratégias de leitura, visando contribuir para a compreensão de textos e uma melhor interiorização da língua escrita. Resultado e Discussão: Com base nos resultados encontrados, acredita-se que essa pesquisa bibliográfica permitirá por meio das estratégias de leitura, que o educando encontre as ferramentas adequadas para lidar com o texto e compreendê-lo, pois, a leitura infantil possibilita ao educando conhecimentos sobre a linguagem oral e escrita. Considerações finais: Conclui-se que o ensino das estratégias de leitura é essencial para o educador abrir caminhos e espaços para que o educando alcance a autonomia leitora de modo que tão logo ele seja capaz de conseguir também a proficiência escrita.

Palavras-chave: Leitura, Literatura Infantil, Compreensão.

\begin{abstract}
Objective: Review scientific literature on the teaching of reading strategies, aiming to contribute to the understanding of texts and a better internalization of written language. Results and Discussion: Based on the results found, it is believed that with this bibliographic research, through children's literature will allow, that the learner will find the appropriate tools to deal with the text and to understand it, because children's literature enables the child to learn about oral and written language. Final considerations: Teaching reading strategies through children's literature is essential for the educator to open paths and spaces for the learner to achieve reading autonomy so that he will be able to achieve written proficiency as well.
\end{abstract}

Keywords: Reading, Children's literature, Understanding.

\section{RESUMEN}

Objetivo: Revisar la literatura científica sobre la enseñanza de las estrategias de lectura ,que contribuye a la comprensión de textos literarios y una mejor interiorización de la lengua escrita. Resultado y Discusión: Basado en los resultados encontrados, créese que esta pesquisa bibliográfica permitirá por medio de la lectura infantil posibilita al niño conocimientos sobre la lenguaje y escrita. Consideraciones finales: Se concluye que la enseñanza de las estrategias de lectura de la literatura infantil es esencial para el educador abrir caminos y espacios para que el educando alcance la autonomía lectora de modo que tan pronto él sea capaz de conseguir también la profesión escrita.

Palabras clave: Lectura, Literatura infantil, La compression.

${ }^{1}$ Doutorado em Letras pela Universidade Federal do Espírito Santo, Brasil.

${ }^{2}$ Mestrado em Gestão Social, Educação e Desenvolvimento Regional pela Faculdade Vale do Cricaré - ES, Brasil. *E-mail: kelienepmsilva@gmail.com

SUBMETIDO EM: 1/2019

ACEITO EM: 2/2019

PUBLICADO EM: 4/2019

REAS/EJCH | Vol. Sup. 23 | e226 | DOI: https://doi.org/10.25248/reas.e226.2019 Página 1 de 8 


\section{INTRODUÇÃO}

A complexidade das dificuldades de aprendizagem em leitura tem sido objeto de estudo de grande relevância entre educadores, que, muitas vezes, se encontram em estado de "confusão" com relação a como avançar. Existe um consenso entre diversos teóricos acerca da temática, de que o cotidiano escolar é um espaço propício ao letramento, e à formação de leitores autônomos (FREIRE P, 2000).

Há que se pensar que talvez a questão não esteja consolidada no que se deve fazer, mas, sim, em como proceder. Nos pensamentos de Freire P (2000), encontra-se um possível caminho, a perpassar uma consolidação ideológica acerca do estudo. Para o autor estudar é quase sempre um fardo, uma obrigação amarga a cumprir; se estudar e ler fossem fontes de alegria e de prazer, resultaria em conhecimentos indispensável para se mover melhor no mundo, assim teríamos índices mais reveladores da qualidade de nossa educação. Este é um esforço que deve começar na Escola Infantil, intensificar-se no período de alfabetização e continuar sem jamais parar.

Para viver em uma sociedade letrada, é essencial ter uma leitura que proporcionem uma emancipação entre educadores e educando, que a cada dia são desafiados pelo mercado de trabalho, a se impor de forma crítica e transformadora, como Lerner D (2008), ler é adentrar em outros mundos possíveis. É interrogar a realidade para entende-la melhor, é se afastar do texto e assumir uma postura crítica frente ao que se diz e ao que se quer dizer, é tirar carta de cidadania no mundo da cultura escrita. Desse modo, pode-se dizer que ler possibilita ao indivíduo, se tornar um cidadão crítico, consciente e independente.

A fim de que sejam formados leitores competentes parece ser necessário, mais do que ensinar o sujeito a decodificar um código linguístico. De acordo com Bittencourt et al. (2015), a ação pedagógica deve ser de enlace do educando com a língua materna, ou seja, com a Língua Portuguesa, e isso já nos primeiros anos do ensino fundamental, por meio da mediação e da intervenção constante da professora, na premissa de suscitar no educando, primeiramente, a compreensão leitora.

Segundo Bittencourt ZA et al. (2015) consolidam, a escola deve oportunizar vivências prazerosas e espontâneas com os livros, constantes e imbuídas de sentidos, que podem ser produzidos se a criança perceber que o que é ensinado na escola tem relação com o que existe fora da escola. Então um dos papéis da escola é associar o ensino de Língua Portuguesa das práticas de leitura e escrita vivenciadas pelas crianças em circunstâncias reais de interações contagiante do seu dia a dia, com os objetivos de ampliar o seu repertório de conhecimento sobre os usos e as funções de diferentes gêneros textuais, despertar o prazer pela leitura e contribuir para a formação do leitor competente.

Assim, Souza RJ et al. (2010), acreditam que os educadores são os agentes principais das práticas leitoras. Por meio de estratégias de compreensão leitora, o educador vai abrindo caminhos e espaços para que o educando alcance autonomia leitora. Desse modo, os educadores necessitam de novas práticas pedagógicas que auxiliam a superar as dificuldades de leitura encontradas nos anos iniciais do Ensino Fundamental.

Diante desse pressuposto surge a seguinte problemática: Que estratégias de leitura os educadores podem utilizar para que o educando alcance a autonomia leitora?

Buscando responder a esse questionamento, objetiva- se descrever as estratégias de leitura com a literatura infantil que pode contribuir para a compreensão de textos literários. Para tal pesquisa será realizado um estudo de cunho bibliográfico visando traçar as estratégias de leitura das teóricas norte-americanas Harvey e Goudvis (2008 apud SOUZA, 2010). 
Com esse estudo de estratégias de leitura, pretende-se contribuir para que os educadores proporcionem aos seus educandos caminhos que os conduzam a compreensão leitora de textos literários.

\section{Leitura}

A leitura tem sido um tema bastante relevante desde a sua origem até os dias de hoje e sua performance modifica-se com o passar tempo como aponta Zilberman R (2001). A leitura compreendida como linguagem é o modo de comunicação mais complexo criado pela humanidade, e que ganha destaque em muitos debates. Entretanto, nem sempre foi assim, pois a leitura chegou a ser conceituada como "maléfica", juntamente com sua "parceria mais qualificada, a literatura" (ZILBERMAN R, 2001).

Zilberman acredita que instruindo o ser humano a pensar e agir com liberdade, ainda que mediado pela fantasia e pelo imaginário, a leitura sinaliza o perigo para a sociedade ou indivíduos autoritários. Diante disso, nunca deixou de ser criminalizada, obstinando o mau, a magia ou o desconhecido temido pelos poderosos. Ao propor a capacidade de fazer mal, ela parece comprovar sua eficiência. Que se manifesta para aqueles que representam, também preferencialmente obras de ficção, os momentos em que ela se mostra benéfica e funcional.

Desse modo, pode-se dizer que a leitura foi considerada um risco à sociedade e por um período de tempo ela ficou limitada aos letrados e sacerdotes, sendo considerada perigosa, pois à leitura excessiva se atribui grave delito: ela transforma e transforma seu leitor. (ZILBERMAN R, 2001). Contudo, mesmo com essa significação negativa, a expansão da leitura se tornou maior.

Em um mundo informatizado, a conotação da leitura perigosa ainda é presente, considerando que os leitores têm uma visão de mundo ampliada. Como relata Zilberman, o único receio que a leitura pode infundir é o de que seus indivíduos sejam levados a alterar sua visão de mundo, sonhem com as possibilidades de transformar a sociedade e não se conformem ao já existente (ZILBERMAN R, 2001).

Portanto, há que se concordar que o papel da escola deve ser o de inserir o sujeito no mundo da leitura Saviani D (1991). No entanto, observa-se que isso não tem se efetivado. Deve-se ressaltar aqui a necessidade de que todos os envolvidos no processo educacional entendam a leitura sobre outra visão, e, não apenas como decodificação de um código escrito.

Ensinar a leitura nas escolas tem sido um desafio, pois muitos métodos tradicionais ainda estão presentes e, segundo Bajard $E$ (2007), esse tipo de prática de extrair o sentido da pronúncia não conduz à compreensão do mesmo.

Mas afinal, o que é leitura? Para compreender o seu significado serão trabalhadas as concepções de alguns autores a seguir.

Bajard E (2002) relata que a leitura é uma ação solitária, silenciosa, de recepção de texto, no entanto, o autor afirma e complementa que o tratamento silencioso do texto tendo em vista atribuir-lhe sentido. Para ele, mesmo sendo um procedimento silencioso, individual, deve ser compartilhado, pois a leitura é um processo com a ação de uma pessoa ativa, pois a interação com o texto ao compreender o sentido dado pelo autor.

Solé I (1998,) diz que a leitura é um processo de interação entre o leitor e o texto que, por sua vez, envolve a presença de um leitor ativo que processa e investiga o texto, com intenção de alcançar alguma finalidade. Diante disso, o autor discorre também que o leitor busca compreender a linguagem escrita, utilizando seus conhecimentos de mundo para entender o conteúdo do texto.

REAS/EJCH | Vol. Sup. 23 | e226 | DOI: https://doi.org/10.25248/reas.e226.2019 Página 3 de 8 
Em concordância com Solé I (1998) está Cosson R (2007), que afirma que o leitor é tão importante quanto o texto, sendo a leitura a consequência de uma interação. Essa interação se dá por intermédio do diálogo que o leitor realiza com o texto afim de compreendê-lo.

Para Kleiman A (2002) a leitura é um processo complexo pois engloba muitos elementos como a percepção, a memória e atenção ler é complexo. A autora ainda menciona como um sistema interativo, no sentido de interação do leitor com o texto para chegar a compreensão.

Bittencourt ZA et al. (2015) afirmam que a leitura permite usufruir de outros mundos, outras vidas, sensações outras. Desse modo ler e adentrar em um novo mundo, um novo horizonte e sentir e entender o outro. Diante dos pressupostos teóricos, torna-se possível entender que ler é, portanto, compreender o texto, por meio de uma interação entre leitor, texto e contexto. A leitura permite ao leitor levar muito de si e extrair vários sentidos. Esse processo está aquém da decodificação das palavras requer a atuação de um sujeito ativo.

$\mathrm{Na}$ concepção de alguns autores, a escola precisa priorizar atividades que estimulem a compreensão leitora. Porém, eles afirmam que muitas vezes isso não é o que de fato acontece. Silva $E$ (2008 et seq.), por exemplo, faz apontamentos sobre a função da leitura e ressalta três problemas visíveis na ação pedagógica dos professores.

De acordo com o autor, o primeiro obstáculo seria a ausência de sentido da leitura, pois muitas vezes esta não ocorre no sentido de melhor compreensão da vida, tornando-se, assim, um suceder de práticas artificiais impostas pela escola como exercício da língua 'culta', análises gramaticais, manifestação de valores, respostas fechadas e pesquisas vazias na biblioteca.

Já no que se refere ao segundo, o articulista descreve que é o de atribuir um único sentido ao texto, imposto pela escola, pelo professor ou pelo livro didático. Isso conduz ao processo chamado pelo autor de homogeneização das consciências (Silva E, 2008, et seq.). Trata-se da escola e do educador sendo possuidores do saber e o educando apenas o receptor. Aqui não se abre espaço para discordâncias de opiniões, para o diálogo e para a pluralidade, que deve estar presente na sala de aula.

Por fim, mas não menos importante, está o terceiro problema: a utilização de textos fragmentados, presentes principalmente nos livros didáticos (Silva E, 2008, et seq.).

Diante desses apontamentos ressaltados pelo estudioso, observa-se a distorção que a escola passa diante da função da leitura e sua importância. E acredita-se que a escola, por sua vez, precisa refletir e reconhecer a importância da aquisição da leitura na vida de todos os seus educandos (Silva E, 2008, et seq.).

\section{Literatura Infantil}

Foi por volta de 1980 que a literatura infantil esteve incorporada gradativamente nas salas de aula. Souza RJ et al. (2010) lembram que a inserção deste gênero, a literatura, produziu novos debates em relação a alfabetização, literatura infantil, aprender e ensinar a ler. Um destes debates, refere-se ao uso da literatura, entre ser literatura apenas ou ser utilizada como material para informar e formar.

Bakhtin M (2003), impressionado com os caminhos de estudos literários de sua época, cita que as relações entre a literatura e cultura não se afastam, tendo em vista que os estudos literários devem estabelecer uma conexão mais estreita com a história da cultura. Desse modo, entende-se que a literatura se interpõe entre a relação da criança com a cultura de sua época, conduzindo tanto ao passado, quanto ao futuro. A criança submergida no seu contexto cultural, precisa do mesmo para apoderar-se da cultura por meio da literatura.

REAS/EJCH | Vol. Sup. 23 | e226 | DOI: https://doi.org/10.25248/reas.e226.2019 Página 4 de 8 
Bakhtin M (2003) também faz menção a dois registros em relação à compreensão de uma obra literária. No primeiro, ele cita que entender uma obra literária não é uma ação fácil, pelo contrário, é uma atividade muito difícil que requer a mobilização de um imenso material, considerando que compreender uma literatura como apresentou seu próprio autor sem sair dos limites da compreensão dele, é uma missão quase impossível. Mas, o estudioso não revela para seus leitores esse imenso material que comenta. Sobre o segundo registro ele descreve que é lidar com a distância temporal e cultural. Inserção do nosso (alheio para o autor) contexto (BAKHTIN M, 2003). Essa distância temporal e cultural exige que o leitor leve em consideração o seu contexto, seus conhecimentos prévios sobre o assunto, pois o leitor precisa fazer uma relação dos dois contextos culturais - o do leitor e do autor, essa relação é de suma importância.

Atribuir sentidos e formular perguntas diante de um texto, são conexões essenciais, pois ao ler é necessário fazer perguntas, mas para perguntar, precisa-se entender o que leu. Desse modo o sentido sempre responde a certas perguntas (BAKHTIN M, 2003). Então, encontra-se respostas para as perguntas se entender o que leu. Dessa forma, o leitor com seu contexto cultural e suas experiências vividas, dá vida ao texto.

Logo, dando ênfase ao fato de que a literatura está ligada ao contexto cultural, de uma forma dialógica, e que é necessário obter algumas técnicas que ajudarão na compreensão e no sentido do texto, não se pode de deixar de pensar sobre como despertar no educando o desejo de se tornar um leitor de literatura infantil (Bakhtin M, 2003).

Nesse ponto, entende-se que ao tornar esse educando um leitor de literatura infantil, se terá no futuro um leitor adulto de textos literários, que a adquire como prática cultural na sua vida social. Segundo Maria (2002) destaca, aqui entra a questão da importância do mediador de leitura que deve atuar para formação desse leitor.

Desse modo, vale ressaltar que o educador, enquanto mediador de leitura, deve despertar em seus educandos o prazer pela leitura, mas primeira precisa se tornar um leitor incessante, permitindo que suas práticas sejam verdadeiras perante as crianças e si mesmo (MARIA L, 2002).

Conforme discorre Maria L (2002), para acompanhar o processo de formação do educando-leitor é imprescindível que o educador tenha construído ou esteja construindo, para si próprio, uma história de leitor.

Alguns autores defendem que o mediador de leitura precisa despertar na criança, o desejo e o prazer pela literatura infantil, pois ao ler, o indivíduo está treinando a mente e estimulando a inteligência. $E$, segundo Goés LP (2010) o progresso da leitura entre crianças resultará em um desenvolvimento progressivo no campo dos valores morais, da cultura da linguagem e no campo racional. O hábito de ler ajuda na formação da opinião e de um espírito crítico, principalmente a leitura de livros que formam o espírito crítico, enquanto a repetição de estereótipos empobrece.

A leitura literária é indispensável às crianças, pois enriquece seus valores, sua linguagem e seu raciocínio. O hábito de ler ajuda na formação de opiniões e de um espírito crítico (GOÉS LP, 2010). Sabe-se que esse é um dos objetivos da escola - preparar o educando para o exercício de sua cidadania, a fim de alcançar uma educação que transforma e liberta, mas, para isso, é necessário formar leitores praticantes e conscientes.

\section{RESULTADOS E DISCUSSÃO}

As estratégias de leitura são um processo que ajuda na motivação, no entendimento e interesse pela leitura. É um meio de ofertar condições afim de que a criança possa observar e ampliar seus conhecimentos de mundo, linguístico e textual (KLEIMAN A, 1989). 
Existem várias estratégias de compreensão de uma leitura, porém, aqui serão ressaltadas as de Harvey e Goudvis (2008 apud SOUZA RJ, 2010). As estratégias desenvolvidas por essas autoras norte-americanas aparecem comentadas e em destaque na obra "Ler e compreender estratégias de leitura", dos autores brasileiros Souza RJ et al. (2010), que também aqui tiveram aqui algumas de suas concepções mencionadas.

Segundo as teóricas Harvey e Goudvis (2008 apud SOUZA RJ, 2010) descrevem, as estratégias para se obter uma melhor compreensão de uma leitura, são: conhecimento prévio, conexões, visualização, inferência, perguntas ao texto, sumarização e síntese.

O conhecimento prévio segundo as autoras é uma estratégia compreendida como a base para as demais pois propicia a relação das conexões entre suas experiências, seu entendimento sobre o mundo e texto. Pois associar o que os leitores sabem para a nova informação é o centro do aprendizado e entendimento. (HARVEY, Goudvis, 2008 apud SOUZA RJ, 2010). Ensinar o conteúdo é tão importante quanto ensinar a forma.

Ao iniciar uma leitura, o leitor permite trazer à tona uma série de informações, sendo assim o conhecimento prévio e conceituado como estratégia-mãe ou estratégia guarda-chuva. (GIROTTO DBA, SOUZA, 2010), pois associa as outras estratégias.

A conexão é uma estratégia onde os educandos realizam conexões com experiências pessoais. Leitores fazem conexões entre os textos lidos e fatos de suas vidas. Segunda as autoras essa ligação entre o que sabem e a leitura é o foco do aprendizado e da compreensão, pois ao comparar um fato de sua vida a um texto passam a entender melhor os pensamentos e sentimentos dos personagens. (Harvey S, Goudvis A, 2008 apud Souza RJ, 2010)

Harvey e Goudvis (2008 apud SOUZA RJ, 2010) separam as conexões da seguinte forma: conexão textoleitor, com a intenção de realizar conexão entre o texto e a vida do leitor. Dessa forma o leitor lembrará de uma situação semelhante que já aconteceu com ele; conexão texto-texto: é quando o leitor ao ler lembra de outro texto lido, conectando grandes ideias e temas entre os textos; conexão texto-mundo: neste momento o leitor estabelece relações daquilo que é lido com situações ocorridas no mundo.

A estratégia definida como visualização é uma forma de compreender significados por intermédio de imagens visuais. Harvey e Goudvis (2008 apud SOUZA RJ, 2010) relatam que as imagens criadas pelos leitores por meio da visualização são pessoais permitindo que a prática da leitura seja prazerosa. O leitor quando visualiza a leitura ele cria imagens mentais, cenários e sons permitindo que elevem o nível de interesse pela leitura.

A inferência é essencial na compreensão para Harvey e Goudvis (2008 apud SOUZA RJ, 2010), Owocki (2003), Fisher, Frey e Lapp (2008) o pensamento inferencial requer uma conclusão ou interpretação que não está explicita no texto, pois os escritores não expressam todos os seus pensamentos em uma página do livro, mostram uma ideia de cada vez permitindo que o leitor faça inferência sobre o mesmo. Inferência seria a capacidade de ler nas entrelinhas.

A estratégia de perguntas/questões ao texto possibilita um contínuo diálogo com o texto Harvey e Goudvis (2008 apud SOUZA RJ, 2010) expõem que ao ler, se elaboram questões referentes ao texto que ao longo da leitura são respondidas. Quanto mais perguntas fizermos maior será a compreensão do texto.

A sumarização é a estratégia em que possibilita ao leitor definir o que é importante no texto, isso é fundamental para a compreensão da leitura. As autoras Harvey e Goudvis (2008 apud SOUZA RJ, 2010) orientam que os leitores devem parar a cada página para pensar sobre o que estão lendo, antes de prosseguir 
com a leitura. Refletir sobre o relevante, detalhar e sintetizar informação ajuda o leitor a produzir significados do texto.

Enfim, aponta-se a estratégia da síntese que é resumir e sintetizar, possibilita atribuir significados às informações importantes que nos cercam no cotidiano. Para Harvey e Goudvis (2008 apud SOUZA RJ, 2010) quando leitores sintetizam informações no momento da leitura, conseguem apresentar o que é mais importante expressando com suas próprias palavras. Isso nos permite a memorizar e atribuir significados.

Trabalhar com as estratégias é um meio de influenciar positivamente os educandos à realizarem suas leituras de forma significativas e prazerosas. Com relação a isso, Souza RJ et al. (2010) explicitam que utilizar as estratégias de leitura com a literatura infantil, é fundamental para a compreensão leitora, pois acredita-se que a literatura é um tipo de texto que permite o leitor mesmo individualmente dialogar com o mundo e os outros.

De acordo com Rildo Cosson (2007) a inclusão do texto literário em uma sociedade acarreta um resultado de "proximidade", consequente do diálogo que ele nos proporciona manter com o mundo e com os outros. Por intermédio da leitura com texto literário, os educandos descobrem as inúmeras leituras que este texto permite e o diálogo que ele estabelece com os outros textos diversos.

Assim, pode-se dizer que trabalhar com as estratégias de leitura possibilita ao leitor ampliar seus conhecimentos, bem como obter a compreensão do texto, pois a compreensão é a base para embarcar completamente na leitura dos livros infantis se tornando leitores autônomas (Souza, et al. 2010).

\section{CONSIDERAÇÕES FINAIS}

Esse artigo permitiu-se reflexões sobre o ensino das estratégias de leitura e sobre a urgência de repensar questões referentes a ela, o que gera mudanças significativas contribuindo assim para uma melhor compreensão dos textos literários. Constatando-se que os pequenos leitores de literatura infantil se formam leitores, pois determinam ligações entre o conjunto de sentidos que formam a sua experiência de vida. Outro fator essencial é o das estratégias de leitura que ajudam na motivação, no entendimento e interesse pela leitura, pois leitores estratégicos realizam uma leitura com atribuição de sentido, objetivação, apropriação e argumentação.

Para se obter uma melhor compreensão de textos literários foi abordado as estratégias de leitura: conhecimento prévio, conexões, visualização, inferência, perguntas ao texto, sumarização e síntese. O ensino das estratégias de leitura precisa ser contínuo, desse modo o educador necessita planejar e definir atividades de leituras com mais frequência afim de que os educandos possam colocar em prática as estratégias de leituras adquiridas, tornando-se assim cidadão crítico, consciente e independente.

\section{REFERÊNCIAS}

1. BAJARD, E. Caminhos da escrita: espaços de aprendizagem. São Paulo: Cortez, 2002.BAJARD, Élie. Da escuta de livros à leitura. São Paulo: Cortez, 2007.

2. BAKHTIN M., Estética da criação verbal. São Paulo: Martins Fontes. 2003.

3. BITTENCOURT, ZA; CARVALHO RS; et al. A compreensão leitora nos anos iniciais - reflexões e propostas de ensino. Petrópolis, Editora Vozes, 2015.

4. COSSON, R. Letramento literário: teoria e prática. São Paulo: Contexto, 2007.

5. FISHER, D. FREY, N. et al. In a Reading State of mind: brain research, teacher modeling, and comprehension instruction. USA: IRA, 2008.

6. FREIRE, P. Professora sim, tia não - Cartas a quem ousa ensinar. 10.ed. São Paulo: Olho D'Água,2000.

7. GIROTTO, CGGS; SOUZA, RJ. Estratégia de leitura: para ensinar alunos a compreender o que leem. In: SOUZA, RJ. et al. Ler e compreender: estratégias de leitura. Campinas - SP, Mercado das Letras, 2010.

8. GÓES, L. P. Introdução à Literatura para crianças e jovens. São Paulo: Paulinas, 2010.

9. KLEIMAN, A. Texto e Leitor: aspectos cognitivos da leitura. Campinas, SP: Pontes, 1989. 
10. KLEIMAN, A. Oficina de leitura: teoria e prática. Campinas: Pontes Editora, 2002.

11. LERNER, D. Ler e escrever na escola: o real, o possível e o necessário. Porto Alegre: Artmed, 2008.

12. MARIA, L. Leitura e colheita - Livros, leitura e formação de leitores. Petrópolis: Vozes, 2002.

13. OWOCKI, F. Comprehension- Strategic Instruction for K-3 stundents. USA: IRA, 2003.

14. SAVIANI, D. Pedagogia Histórico-crítica: primeiras aproximações. 2 ed. São Paulo: Cortez: Autores Associados, 1991.

15. SILVA, E. Theodoro D. A produção da leitura na escola: pesquisas e propostas. São Paulo: Ática, 2008.

16. SOLÉ, I. Estratégias de leitura. Porto Alegre: Artmed, 1998.

17. SOUZA, RJ. et al. Ler e compreender: estratégias de leitura. Campinas, SP: Mercado de letras, 2010. Outros autores: Ana Maria da CS. Menin, CGGS, GIROTTO, DBA. (apud) HARVEY, S; GOUDVIS, A. Strategies that work. Teaching comprehension for understanding and engagement. USA: Stenhouse Publishers \& Pembroke Publishers, 2008.

18. ZILBERMAN, R. Fim do livro, fim dos leitores? São Paulo: Editora SENAC, 2001. 